\title{
Energy Efficiency Metrics of University Data Centers
}

\author{
Leonel Hernandez $^{\text {a, } 1, *}$, Genett Jimenez ${ }^{\text {a, } 2}$, Piedad Marchena ${ }^{\text {a, } 3}$ \\ a Institución Universitaria ITSA, Carrera 45 \# 48-31, Barranquilla, Colombia \\ Ilhernandezc@itsa.edu.co*; gjimenez@itsa.edu.co; ${ }^{3}$ pmarchena@itsa.edu.co \\ * corresponding author
}

\section{ARTICLE INFO}

Article history:

Received 15 July 2018

Revised 5 August 2018

Accepted 8 August 2018

Published online 31 August 2018

\section{Keywords:}

Energy

Green Data Center

Performance Metrics

HVAC System

PUE

DCiE

Environment

\section{ABSTRACT}

The data centers are fundamental pieces in the network and computing infrastructure, and evidently today more than ever they are relevant. Since they support the processing, analysis, assurance of the data generated in the network and by the applications in the cloud, which every day increases its volume thanks to technologies such as Internet of Things, Virtualization, and cloud computing, among others. Precisely the management of this large volume of information makes the data centers consume a lot of energy, generating great concern to owners and administrators. Green Data Centers offer a solution to this problem, reducing the impact produced by the data centers in the environment, through the monitoring and control of these. The metrics are the tools that allow us to measure in our case the energy efficiency of the data center and evaluate if it is friendly to the environment. These metrics will be applied to the data centers of the ITSA University Institution, Barranquilla and Soledad campus, and the analysis of these will be carried out. In previous research, the most common metric (PUE) was analyzed to measure the efficiency of the data centers, to verify if the University's data center is friendly to the environment. It is planned to extend this study by carrying out an analysis of several metrics to conclude which is the most efficient and which allows defining the guidelines to update or convert the data center in a friendly environment.

This is an open access article under the CC BY-SA license (https://creativecommons.org/licenses/by-sa/4.0/).

\section{Introduction}

In a short time, the Internet changed our way of life, the way we work, have fun or learn, making the data more valuable. Likewise, emerging technologies such as the Internet of Things (IoT), Cloud Computing and Virtualization, Programming Network, Big Data, and Digital Transformation have promoted the existence of large data centers responsible for the secure storage of data.

As Baccour says [1], data centers use the network between $5 \%$ and $25 \%$, and therefore the energy consumed by inactive devices is wasted. Data centers, composed of many servers, can absorb as much power as a small city, in fact, numerous studies have shown that average server utilization is usually less than $30 \%$ of maximum utilization [2]. On the other hand, the efficient use of electric power is gaining relevance due to the growing demand and the reduction of resources, and the concern about the environmental impact generated by the increase in data centers, which is why it is necessary to promote the efficient use of electrical energy, based on the quantification of different energy efficiency metrics.

A few years ago, the concept of energy efficiency in data centers was very subjective, since it was often not clear how to measure energy, where it should be estimated or what units to use [3]. For this reason, energy efficiency metrics were developed to convert Data Centers into "Green Data Centers," friendly to the environment. Some of these metrics, applied to the Data Centers of the University Institution ITSA, which will be analyzed in this study include: Data Center Infrastructure Efficiency (DCiE), Power Usage Effectiveness (PUE), HVAC System Effectiveness and Space, Watts and Performance (SWaP), which verifies if they are friendly to the environment. 


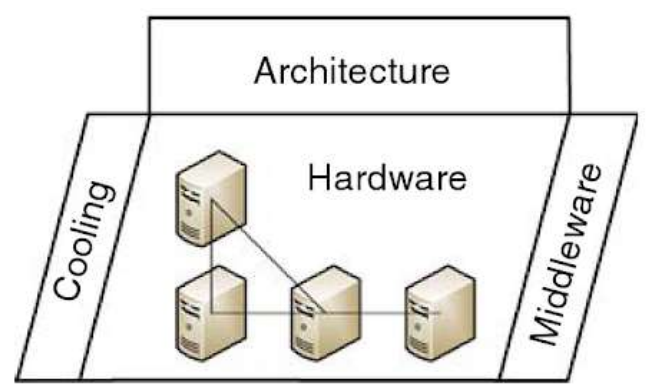

Fig. 1. Areas where the power consumption of Data Centers can be reduced [4]

A Green Data Center is defined as one in which the mechanical systems, electrical, lighting and computation are designed for maximum efficiency and environmental impact [3]. The core of the internet, or of any technological infrastructure of an entity or company, is the data center. The amount of data they process increases as users' needs demand more storage capacity, speed of transmission and processing of information. This trend will continue to grow, which is why data centers can generate a high impact on the environment due to the advanced cooling, lighting and temperature systems they use. Due to this, metrics have been defined that provide guidelines to follow for the design and implementation of green data centers, friendly to the environment. Many factors contribute to the increase of energy consumption in a data center, but there are also some areas in which you can reduce energy consumption, as shown in Fig. 1 [4].

Emerging technologies such as virtualization and cloud and fog computing have contributed to the design of efficient data centers, reducing energy consumption, the use of space, and environmental requirements, even so, some metrics allow measuring the energy consumption of the data centers and thus verify if these are Green Data Centers.

For some years it has become evident the increase in the number of data centers and their size, and with it, the increase in the use of energy. According to [5] in its report on energy use in data centers in the United States, in 2006, data centers consumed $61 \mathrm{kWh}$ (equivalent to the consumption of 5.8 million American households), while in 2008, that figure increased to $69 \mathrm{kWh}$. According to this report, it is expected that between 2014 and 2020, the increase in the use of energy will be $4 \%$, which is equivalent to 73 billion $\mathrm{kWh}$ in 2020 , which shows the excessive consumption of energy required for its operation. This excessive energy consumption affects not only the supplier's economy but also becomes a social and environmental problem, to the extent that resources are consumed indiscriminately.

The infrastructure of the data center building currently accounts for almost half of the total energy consumption, as shown in Fig. 2. In a previous research at the University, Reference [6] designed and implemented a prototype of sensors for the detection of environmental variables in a data center (temperature, humidity, current). The prototype was implemented in the data center of the Barranquilla

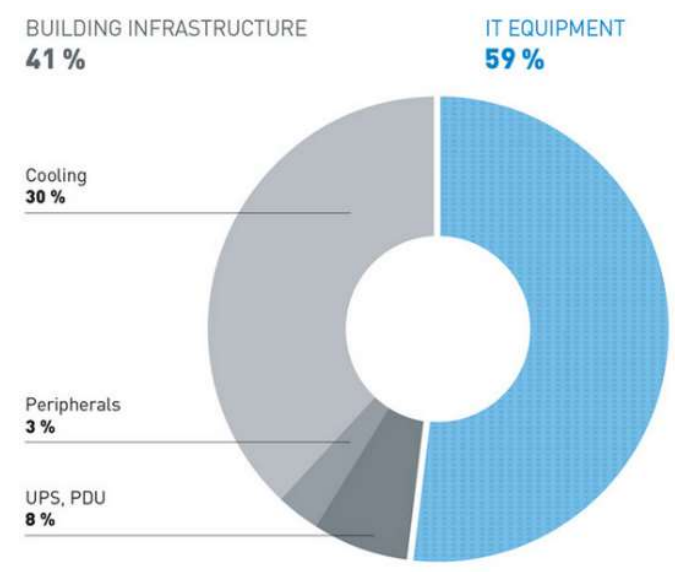

Fig. 2. Energy consumption in the data center building 
campus, and its objective is to control, monitor and notify when events happen that go beyond a defined threshold. The sensors are connected to the WiFi network, which in turn connects to the institutional network. The results can be seen in an application that is currently in the testing phase.

In our environment, some research has been carried out regarding the impact that the devices and elements that make up a data center on the environment can produce. However, companies have not yet been fully aware of this impact, and when designing and building a data center, the environmental element is not considered. This study seeks to create sensitivity with respect to this situation, beginning by analyzing the state of the two data centers of the University, to contribute to research in this field and draw up a plan for improvement, given that the analysis of the various Metrics has shown that our data centers are not friendly to the environment. This study can be replicated in other educational Institutions and in companies of the productive sector that each one begins by analyzing their infrastructure and carrying out strategic planning that contributes to the improvement of the environment.

The paper is organized as follows. After having contextualized the reader with the theme of the project in the introduction, a basic review of the literature about the green data centers is made. Continue with the research method used to make way for calculations of the most relevant metrics in our data centers. It concludes with a concise analysis of the results and possible future work that can be developed from this work.

\section{Methods}

For the elaboration of this project, the methodology of descriptive and non-experimental research was used [7]. Descriptive since all the documentation related to green data center have been reviewed Not experimental because it focuses on the study of the reality of the data centers of the University in its natural dynamics. The study does not create situations to observe what changes in the environment from a created situation but seek to describe, explain and predict reality, from an approach.

The research design to be developed in the project corresponds to a qualitative, transactional design. Qualitative because it is based on a working hypothesis, defined as that the data centers of the Institution are not friendly to the environment, which goes in the opposite direction to the institutional guideline of care for the environment. It is transactional because the measurements are taken in a single moment of time. For each metric, the tabulated results will be shown, after the application of the respective formulas, for each location. It is expected in the future to perform a multivariate statistical analysis to compare the gap between the real values versus the standard values of each metric reviewed in this study.

\section{Results and Discussions}

As noted above, the data centers consume a significant amount of energy, according to Wang, [8], the taxonomy of performance metrics of "green computing" is defined, shown in Fig. 3, which verifies

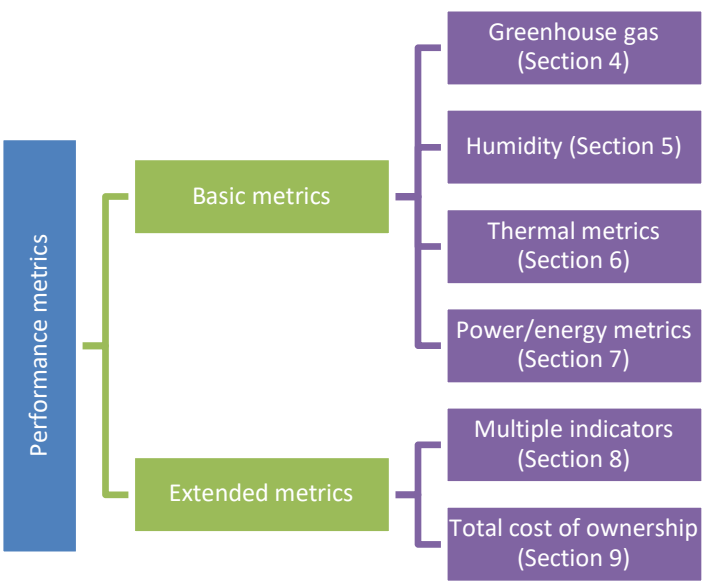

Fig. 3. Taxonomy of "Green Computing" performance metrics [8] 
Table 1. Devices of the Data Center of the University Institution ITSA - Campus Soledad and Barranquilla

\begin{tabular}{ccccc}
\hline \multirow{2}{*}{ No } & Device & Description & \multicolumn{2}{c}{ IT device quantity } \\
\cline { 3 - 4 } & & Sophos WG450 & Soledad & Barranquilla \\
\hline 1 & Firewall & CISCO 2960 & 3 & 2 \\
3 & Switch & QUIDWAY S3300 & 1 & \\
4 & Switch & TPLINK TL-SG3424 & 1 & \\
5 & Switch & HP StorageWorks P2000 & 2 & 1 \\
6 & Router & CISCO 2900 & 1 & \\
7 & Servers & HP. PROLIANT DL 380P GEN8 & 3 & 1 \\
8 & Conditioned air & ComfortStar & 1 & 1 \\
9 & UPS & GALLEON X9B 6K & & 1 \\
10 & Switch & HuaweiS2300 & & 1 \\
11 & Switch & Catalyst3560 & & \\
12 & Transceiver & RaisecomRC001 & & \\
13 & Router & Cisco 3925 & & \\
\hline
\end{tabular}

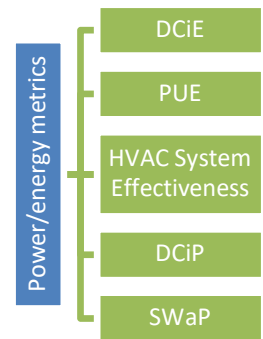

Fig. 4. Taxonomy of power consumption metrics [8]

if a data center is or not green. For this study, an emphasis was placed on the primary metrics, precisely the power, and energy metrics, considering the characteristics of the data centers that were evaluated.

\section{A. Power/Energy Metrics}

A data center is a special building, which is used to house computer systems, and these are associated with components such as telecommunications and storage systems, backup power sources, redundant communication connections, environmental controls and security devices. The energy consumption varies greatly, depending on that building [9]. For this reason, it is essential to identify the components and devices that make up the data centers of the ITSA University Institution.

The ITSA University Institution has two data centers, one on the Soledad campus, and the other on the Barranquilla campus. Table 1 lists the devices that make up the data centers of the Soledad and Barranquilla campuses, correspondingly, of the ITSA University Institution. The power/energy metrics defined are those shown in Fig. 4. Considering the data collected in the data centers of the University Institution ITSA, an analysis is made of the energy efficiency of these, based on the metrics: Efficiency of the data center infrastructure (DCie), Efficiency of the use of the Power (PUE), Efficiency of the HVAC system, and SWaP.

\section{B. Data Center Infrastructure Efficiency Metric (DCiE)}

The data center infrastructure efficiency metric (Data Center Infrastructure Efficiency-DCiE) is a metric widely accepted by the Green Grid to help IT professionals determine the energy efficiency of data centers and monitor the impact of its efficiency efforts [10], is given by (1):

$$
D C i E=\frac{\text { Power Total Equipment IT }}{\text { Power Total Equipment Data Center }}(\text { watts })
$$

The higher the value of the $\mathrm{DCiE}$, the more efficient the data center infrastructure, the best practice is that this value is above $70 \%$ [8] and should never be greater than $100 \%$ [11]. According to Green Grid, the efficiency of the use of the power is measured by levels of efficiency, as shown in Table 2. 
Table 2. Levels of Efficiency according to Green Grid

\begin{tabular}{ccc}
\hline PUE & DCiE & Levels of Efficiency \\
\hline 3,0 & $33 \%$ & Very Inefficient \\
2,5 & $40 \%$ & Inefficient \\
2,0 & $50 \%$ & Average \\
1,5 & $67 \%$ & Efficient \\
1,2 & $83 \%$ & Very Efficient \\
\hline
\end{tabular}

Table 3. Calculation of the DCiE in the Data Center of the Barranquilla Campus

\begin{tabular}{|c|c|c|c|c|}
\hline Quantity & Device & Description & Consumption Unit & Total Consumption \\
\hline 1 & Switch & Huawei s2300 & $12.8 \mathrm{~W}-38 \mathrm{~W}$ & $38 \mathrm{~W}$ \\
\hline 2 & Switch & Catalyst2960 & $464 \mathrm{~W}-870 \mathrm{~W}$ (con PoE) & $1.740 \mathrm{~W}$ \\
\hline 1 & Switch & Catalyst 3560 & $449 \mathrm{~W}$ & $449 \mathrm{~W}$ \\
\hline 1 & Transceiver & Raisecomrc001 & $36 \mathrm{~W}-72 \mathrm{~W}$ DC & $72 \mathrm{~W}$ \\
\hline 1 & Router & Cisco 3925 & $85 \mathrm{~W}-400 \mathrm{~W}$ & $400 \mathrm{~W}$ \\
\hline \multicolumn{4}{|c|}{ Total Consumption of IT } & $2.699 \mathrm{~W}$ \\
\hline 1 & Conditioned air & ComfortStar & $5290 \mathrm{~W}$ & $5.290 \mathrm{~W}$ \\
\hline \multicolumn{4}{|c|}{ Total Consumption of Data Center } & $7.989 \mathrm{~W}$ \\
\hline \multicolumn{4}{|c|}{ DCiE Barranquilla } & $33.78 \%$ \\
\hline
\end{tabular}

Table 4. Calculation of the DCiE in the Data Center of the Soledad Campus

\begin{tabular}{|c|c|c|c|c|}
\hline Quantity & Device & Description & Consumption Unit & Total Consumption \\
\hline 2 & Firewall & Sophos WG450 & $66 \mathrm{~W}-180 \mathrm{~W}$ & $360 \mathrm{~W}$ \\
\hline 2 & Switch & Cisco 2960 & $464 \mathrm{~W}-870 \mathrm{~W}$ (con PoE) & $1.740 \mathrm{~W}$ \\
\hline 1 & Switch & Quidway s3300 & $100 \mathrm{~V}-264 \mathrm{~V}$ & $264 \mathrm{~W}$ \\
\hline 1 & Switch & TPLINK TL-SG3424 & $100 \mathrm{~V}-240 \mathrm{~V}$ & $240 \mathrm{~W}$ \\
\hline 1 & Switch & Cisco 2960 & $464 \mathrm{~W}-870 \mathrm{~W}$ (con PoE) & $870 \mathrm{~W}$ \\
\hline 2 & Storage & HP StorageWorks P2000 & $374 \mathrm{~W}-432 \mathrm{~W}$ & $390 \mathrm{~W}$ \\
\hline 1 & Router & Cisco 2900 & $80 \mathrm{~W}-360 \mathrm{~W}$ & $360 \mathrm{~W}$ \\
\hline 3 & Servers & HP Proliant DL 380P GEN8 & $460 \mathrm{~W}, 750 \mathrm{~W}-1200 \mathrm{~W}$ & $3.600 \mathrm{~W}$ \\
\hline \multicolumn{4}{|c|}{ Total Consumption of IT } & $7.824 \mathrm{~W}$ \\
\hline 1 & Conditioned air & ComfortStar & $5290 \mathrm{~W}$ & $5.290 \mathrm{~W}$ \\
\hline 1 & UPS & Galleon X9B 6K & $5400 \mathrm{~W}$ & $5.400 \mathrm{~W}$ \\
\hline \multicolumn{4}{|c|}{ Total Consumption of Data Center } & 18.514 W \\
\hline \multicolumn{4}{|c|}{ DCiE Soledad } & $42.26 \%$ \\
\hline
\end{tabular}

The measurements were taken in the data center of the Barranquilla campus of the University Institution ITSA, and the data necessary to calculate the PUE are related in Table 3. The measure of the infrastructure efficiency of the Barranquilla campus is $33.78 \%$, which indicates that it is inefficient, as established in Table 3, which suggests that measures must be taken in this regard. The measurements were taken in the data center of the Soledad campus of the University Institution ITSA, and the data necessary to calculate the DCiE are listed in Table 4. The measure of the efficiency of the Soledad campus infrastructure is $42.26 \%$, which indicates that the use of the power in said campus is average, as established in Table 3, it is advisable to follow up.

\section{Power Usage Effectiveness (PUE)}

The Power Usage Effectiveness-PUE metric is a metric that allows measuring the efficiency in the use of the energy of a data center, was created by the Green Grid Organization, and is calculated using the Eq. (2):

$$
\text { PUE }=\frac{\text { Total Power Equipment Data Center }}{\text { Total Power IT Equipment }}(\text { watts })
$$


The PUE value indicates the relationship between the energy used by IT equipment and the energy consumed by all data center equipment, for example, the air conditioners needed to maintain the temperature necessary for IT equipment to work safely. The PUE, which is an instantaneous representation of the consumption of electrical energy, which transmits an understanding of the minimum possible use of energy; therefore, the average method of these metrics is proposed over a significant period, for example, one year, to understand the energy efficiency of the data center better and to develop energy rating / rating systems [12].

The higher the PUE value, the lower the efficiency of the installation as more "overload" energy is consumed to feed the electrical load. The ideal PUE value is 1, which indicates the maximum achievable efficiency without overload energy [9]. This metric has one disadvantage: it only measures the efficiency of the construction infrastructure that supports a given data center and does not indicate anything about the efficiency of the IT equipment itself [5]. The measurements were taken in the data center of the Barranquilla campus of the University Institution ITSA, and the data necessary to calculate the PUE are listed in Table 5.

The measure of the efficiency of the use of power in the Barranquilla campus is 2.96, which indicates that the use of power in the Barranquilla campus is inefficient, as established in Table 3 , which suggests that measures must be taken about. The measurements were taken in the data center of the Soledad campus of the University Institution ITSA, and the data necessary to calculate the PUE are listed in Table 6.

The measure of the efficiency of the use of the power in the campus is 2.37 , which indicates that the use of the power in said campus is average, according to that established in Table 3 , it is advisable to follow up.

Table 5. Calculation of the PUE in the Data Center of the Barranquilla Campus

\begin{tabular}{|c|c|c|c|c|}
\hline Quantity & Device & Description & Consumption Unit & Total Consumption \\
\hline 1 & Switch & Huawei s2300 & $12.8 \mathrm{~W}-38 \mathrm{~W}$ & $38 \mathrm{~W}$ \\
\hline 2 & Switch & Catalyst2960 & $464 \mathrm{~W}-870 \mathrm{~W}(\operatorname{con} \mathrm{PoE})$ & $1.740 \mathrm{~W}$ \\
\hline 1 & Switch & Catalyst 3560 & $449 \mathrm{~W}$ & $449 \mathrm{~W}$ \\
\hline 1 & Transceiver & Raisecomrc001 & $36 \mathrm{~W}-72 \mathrm{~W}$ DC & $72 \mathrm{~W}$ \\
\hline 1 & Router & Cisco 3925 & $85 \mathrm{~W}-400 \mathrm{~W}$ & $400 \mathrm{~W}$ \\
\hline \multicolumn{4}{|c|}{ Total Consumption of IT } & $2.699 \mathrm{~W}$ \\
\hline 1 & Conditioned air & ComfortStar & $5290 \mathrm{~W}$ & $5.290 \mathrm{~W}$ \\
\hline \multicolumn{4}{|c|}{ Total Consumption of Data Center } & $7.989 \mathrm{~W}$ \\
\hline \multicolumn{4}{|c|}{ PUE Barranquilla } & $2.96 \%$ \\
\hline
\end{tabular}

Table 6. Calculation of the PUE in the Data Center of the Soledad Campus

\begin{tabular}{|c|c|c|c|c|}
\hline Quantity & Device & Description & Consumption Unit & Total Consumption \\
\hline 2 & Firewall & Sophos WG450 & $66 \mathrm{~W}-180 \mathrm{~W}$ & $360 \mathrm{~W}$ \\
\hline 2 & Switch & Cisco 2960 & $464 \mathrm{~W}-870 \mathrm{~W}$ (con PoE) & $1.740 \mathrm{~W}$ \\
\hline 1 & Switch & Quidway s3300 & $100 \mathrm{~V}-264 \mathrm{~V}$ & $264 \mathrm{~W}$ \\
\hline 1 & Switch & TPLINK TL-SG3424 & $100 \mathrm{~V}-240 \mathrm{~V}$ & $240 \mathrm{~W}$ \\
\hline 1 & Switch & Cisco 2960 & $464 \mathrm{~W}-870 \mathrm{~W}$ (con PoE) & $870 \mathrm{~W}$ \\
\hline 2 & Storage & HP StorageWorks P2000 & $374 \mathrm{~W}-432 \mathrm{~W}$ & $390 \mathrm{~W}$ \\
\hline 1 & Router & Cisco 2900 & $80 \mathrm{~W}-360 \mathrm{~W}$ & $360 \mathrm{~W}$ \\
\hline 3 & Servers & HP. Proliant DL 380P GEN8 & $460 \mathrm{~W}, 750 \mathrm{~W}-1200 \mathrm{~W}$ & $3.600 \mathrm{~W}$ \\
\hline \multicolumn{4}{|c|}{ Total Consumption of IT } & $7.824 \mathrm{~W}$ \\
\hline 1 & Conditioned air & ComfortStar & $5290 \mathrm{~W}$ & $5.290 \mathrm{~W}$ \\
\hline 1 & UPS & Galleon X9B 6K & $5400 \mathrm{~W}$ & $5.400 \mathrm{~W}$ \\
\hline \multicolumn{4}{|c|}{ Total Consumption of Data Center } & $18.514 \mathrm{~W}$ \\
\hline \multicolumn{4}{|c|}{ PUE Soledad } & $2.37 \%$ \\
\hline
\end{tabular}




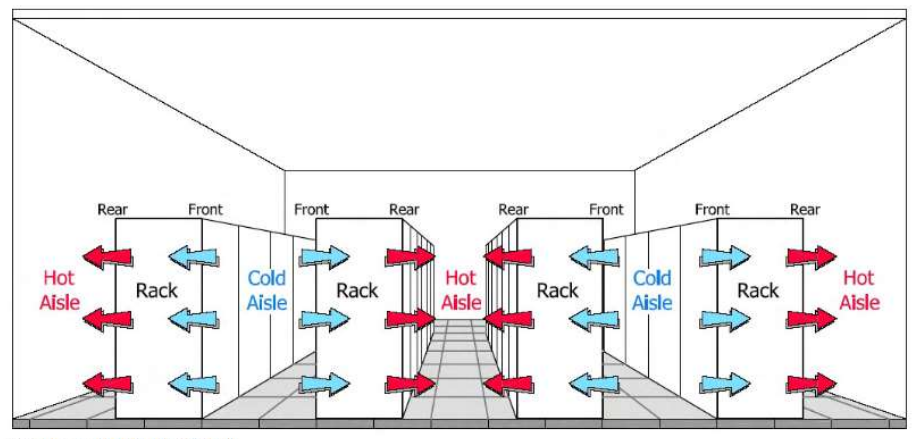

Source: ASHRAE (2004)

Fig. 5. Typical hot / cold aisle design [13]

\section{HVAC System Efficiency Metric}

The HVAC system (heater, fan and air conditioning) is the fraction of the data center that is responsible for maintaining appropriate environmental conditions for the proper functioning of the devices included in the data center. A typical data center includes air conditioning, ventilation, a large central plant, lights, and mirror loads [8]. The designs of the data centers are varied; however, a typical design or good practice, implies that the cabinets are organized as islands, so that the use of resources can be optimized, as shown in Fig. 5 [13].

The efficiency metric of the HVAC system is calculated by establishing the relationship between the energy consumption of the IT equipment of the data center between the consumption of the HVAC system added to the amount of fuel, steam and chilled water multiplied by 293, as shown in Eq. (3):

$$
\text { HVAC_Efficiency }=\frac{\text { Energy_IT_Equipment }}{\text { Energy_HVAC+293*(Fuel+Steam }+ \text { Wa }}
$$

A low value of HVAC efficiency implies that the HVAC system is using a high amount of energy, and therefore has a high potential to be optimized. According to a database of data centers surveyed by Lawrence Berkeley National Laboratory, the effectiveness of the HVAC system can vary from 0.6 to 3.5 [14], as outlined in Table 7.

Since the data centers of the University Institution ITSA does not use cooling mechanisms such as fuel, steam or ice water, the relationship on which the calculation of the relationship between the amount of energy consumed by IT devices and the quantity is based on energy consumed by HVAC devices. The measurements were taken in the data centers of the Barranquilla and Soledad campus of the ITSA University Institution, and the data necessary to calculate the HVAC efficiency are listed in Tables 8 and 9 .

Table 7. HVAC efficiency levels according to the study conducted by Lawrence Berkeley National Laboratory

\begin{tabular}{cc}
\hline HVAC Effciency & Efficiency Level \\
\hline 0,7 & Standard \\
1,4 & Good \\
2,5 & Best \\
\hline
\end{tabular}

Table 8. Calculation of the HVAC in the Data Center of the Barranquilla Campus

\begin{tabular}{|c|c|c|c|c|}
\hline Quantity & Device & Description & Consumption Unit & Total Consumption \\
\hline 1 & Switch & Huawei s2300 & $12.8 \mathrm{~W}-38 \mathrm{~W}$ & $38 \mathrm{~W}$ \\
\hline 2 & Switch & Catalyst2960 & $464 \mathrm{~W}-870 \mathrm{~W}$ (con PoE) & $1.740 \mathrm{~W}$ \\
\hline 1 & Switch & Catalyst3560 & $449 \mathrm{~W}$ & $449 \mathrm{~W}$ \\
\hline 1 & Transceiver & Raisecomrc001 & $36 \mathrm{~W}-72 \mathrm{~W} \mathrm{DC}$ & $72 \mathrm{~W}$ \\
\hline 1 & Router & Cisco 3925 & $85 \mathrm{~W}-400 \mathrm{~W}$ & $400 \mathrm{~W}$ \\
\hline \multicolumn{4}{|c|}{ Total Consumption of IT } & $2.699 \mathrm{~W}$ \\
\hline 1 & Conditioned air & ComfortStar & $5290 \mathrm{~W}$ & $5.290 \mathrm{~W}$ \\
\hline \multicolumn{4}{|c|}{ Total Consumption of Data Center } & $7.989 \mathrm{~W}$ \\
\hline \multicolumn{4}{|c|}{ HVAC Barranquilla } & $1.51 \%$ \\
\hline
\end{tabular}


Table 9. Calculation of the HVAC in the Data Center of the Soledad Campus

\begin{tabular}{|c|c|c|c|c|}
\hline Quantity & Device & Description & Consumption Unit & Total Consumption \\
\hline 2 & Firewall & Sophos WG450 & $66 \mathrm{~W}-180 \mathrm{~W}$ & $360 \mathrm{~W}$ \\
\hline 2 & Switch & Cisco 2960 & $464 \mathrm{~W}-870 \mathrm{~W}$ (con PoE) & $1.740 \mathrm{~W}$ \\
\hline 1 & Switch & Quidway s3300 & $100 \mathrm{~V}-264 \mathrm{~V}$ & $264 \mathrm{~W}$ \\
\hline 1 & Switch & TPLINK TL-SG3424 & $100 \mathrm{~V}-240 \mathrm{~V}$ & $240 \mathrm{~W}$ \\
\hline 1 & Switch & Cisco 2960 & $464 \mathrm{~W}-870 \mathrm{~W}$ (con PoE) & $870 \mathrm{~W}$ \\
\hline 2 & Storage & HP StorageWorks P2000 & $374 \mathrm{~W}-432 \mathrm{~W}$ & $390 \mathrm{~W}$ \\
\hline 1 & Router & Cisco 2900 & $80 \mathrm{~W}-360 \mathrm{~W}$ & $360 \mathrm{~W}$ \\
\hline 3 & Servers & HP. Proliant DL 380P GEN8 & $460 \mathrm{~W}, 750 \mathrm{~W}-1200 \mathrm{~W}$ & $3.600 \mathrm{~W}$ \\
\hline \multicolumn{4}{|c|}{ Total Consumption of IT } & $7.824 \mathrm{~W}$ \\
\hline 1 & Conditioned air & ComfortStar & $5290 \mathrm{~W}$ & $5.290 \mathrm{~W}$ \\
\hline 1 & UPS & Galleon X9B 6K & $5400 \mathrm{~W}$ & $5.400 \mathrm{~W}$ \\
\hline \multicolumn{4}{|c|}{ Total Consumption of Data Center } & $18.514 \mathrm{~W}$ \\
\hline \multicolumn{4}{|c|}{ HVAC Soledad } & $3.5 \%$ \\
\hline
\end{tabular}

The measure of the efficiency of the HVAC system in the Barranquilla campus is 1.51 , which indicates its effectiveness is better, compared to other metrics, and therefore its potential for optimization is minimal, as established in Table 8. Also, the measure of the efficiency of the HVAC system in the Soledad campus is 3.5, which indicates its effectiveness is good, and that it has the potential to be optimized.

\section{E. Metrics of Space Efficiency, Watts and Performance (SWAP)}

The space efficiency, power and performance metric ( $\mathrm{SWaP}$ ) allows measuring the energy efficiency of the reference performance of the server contrasted with the product of the energy consumed by the space used, measured in rack units (RU), as appreciates in the Eq. (4):

$$
\text { SWaP }=\frac{\text { Perfomance }}{\text { Space } * \text { Energy Consumption }}
$$

Sun introduced the Swap metric; it allows to compare the efficiency of the servers regarding space and energy consumption; however, this metric can be applied to network equipment or storage [14]. In the case of the data centers of the ITSA University Institution, the measurements were made by devices and by the rack, including servers, network and storage devices, as shown in Tables 10 and 11.

When comparing the SWaP value of the switches located in the Barranquilla data center, it is evident that the Huawei S2300 switch is more efficient concerning space and power consumption than the other installed switch models (Cisco Catalyst 2960 and Cisco Catalyst 3560).

Table 10. Calculation of the SWAP in the Data Center of the Barranquilla Campus

\begin{tabular}{|c|c|c|c|c|c|c|c|c|c|}
\hline Qty & Device & Description & $\begin{array}{c}\text { Unit } \\
\text { Consumption }\end{array}$ & $\begin{array}{r}\text { Total } \\
\text { Consumption }\end{array}$ & $\begin{array}{r}\text { Unit } \\
\text { Performance } \\
(\mathrm{W}) \\
\end{array}$ & $\begin{array}{r}\text { Total } \\
\text { Performance } \\
(\mathrm{W}) \\
\end{array}$ & $\begin{array}{r}\text { RU } \\
\text { per } \\
\text { device }\end{array}$ & $\begin{array}{r}\text { RU } \\
\text { Total }\end{array}$ & $\begin{array}{r}\text { SWAP } \\
(\%)\end{array}$ \\
\hline 1 & Switch & $\begin{array}{l}\text { Huawei } \\
\text { S2300 }\end{array}$ & $12.8-38 \mathrm{~W}$ & 38 & 38 & 38 & 1 & 1 & 100.00 \\
\hline 2 & Switch & $\begin{array}{l}\text { Catalyst } \\
2960\end{array}$ & $\begin{array}{l}464-870 \mathrm{~W} \\
(\mathrm{con} \mathrm{PoE})\end{array}$ & 1740 & 370 & 740 & 1 & 2 & 21.26 \\
\hline 1 & Switch & $\begin{array}{l}\text { Catalyst } \\
3560\end{array}$ & $449 \mathrm{~W}$ & 449 & 60 & 60 & 1 & 1 & 13.36 \\
\hline 1 & Transceiver & $\begin{array}{l}\text { Raisecom } \\
\text { RC001 }\end{array}$ & $36-72 \mathrm{~W}$ DC & 72 & 15 & 15 & 2 & 2 & 10.42 \\
\hline \multirow[t]{2}{*}{1} & Router & $\begin{array}{l}\text { Cisco } \\
3925\end{array}$ & $85-400 \mathrm{~W}$ & 400 & 100 & 100 & 1 & 1 & 25.00 \\
\hline & Total & & & 2699 & & 953 & & 7 & 5.04 \\
\hline
\end{tabular}


Table 11. Calculation of the SWAP in the Data Center of the Soledad Campus

\begin{tabular}{|c|c|c|c|c|c|c|c|c|c|}
\hline Qty & Device & Description & $\begin{array}{l}\text { Unit } \\
\text { Consumption }\end{array}$ & $\begin{array}{r}\text { Total } \\
\text { Consumption }\end{array}$ & $\begin{array}{r}\text { Unit } \\
\text { Performance } \\
\text { (W) }\end{array}$ & $\begin{array}{r}\text { Total } \\
\text { Performance } \\
\text { (W) }\end{array}$ & $\begin{array}{r}\text { RU } \\
\text { per } \\
\text { device }\end{array}$ & $\begin{array}{r}\text { RU } \\
\text { Total }\end{array}$ & $\begin{array}{r}\text { SWAP } \\
(\%)\end{array}$ \\
\hline 2 & Firewall & $\begin{array}{l}\text { Sophos } \\
\text { WG450 }\end{array}$ & $66-180 \mathrm{~W}$ & 360 & 83 & 166 & 1 & 2 & 23.06 \\
\hline 3 & Switch & $\begin{array}{l}\text { Catalyst } \\
2960\end{array}$ & $\begin{array}{l}464-870 \mathrm{~W} \\
(\text { con PoE) }\end{array}$ & 2610 & 370 & 1110 & 1 & 3 & 14.18 \\
\hline 1 & Switch & $\begin{array}{l}\text { Quidway } \\
\text { S3300 }\end{array}$ & $100-264 \mathrm{~V}$ & 264 & 92 & 92 & 1 & 1 & 34.85 \\
\hline 1 & Switch & $\begin{array}{l}\text { TP Link } \\
\text { TL-SG3424 }\end{array}$ & $100-240 \mathrm{~V}$ & 240 & 23.3 & 23.3 & 1 & 1 & 9.71 \\
\hline 2 & Storage & $\begin{array}{l}\text { HP Storage } \\
\text { Works } \\
\text { P2000 }\end{array}$ & $374-432 W$ & 390 & 390 & 780 & 2 & 4 & 50.00 \\
\hline 1 & Router & $\begin{array}{l}\text { Cisco } \\
2900\end{array}$ & $80-360 \mathrm{~W}$ & 360 & 210 & 210 & 1 & 1 & 58.33 \\
\hline 3 & Servidores & $\begin{array}{l}\text { HP. Proliant } \\
\text { DL 380P } \\
\text { GEN8 }\end{array}$ & $\begin{array}{l}460,750- \\
1200 \mathrm{~W}\end{array}$ & 3600 & 1200 & 3600 & 1 & 3 & 33.33 \\
\hline & Total & & & 7824 & & 5981,3 & & 15 & 5,10 \\
\hline
\end{tabular}

When comparing the SWaP value of the switches located in Soledad's data center, it is evident that the Quidway S3300 switch is more efficient regarding space and power consumption than the other installed switch models (Cisco Catalyst 2960 and TP Link TL -SG3424). On the other hand, the SWaP of the routers shows that the router located in Soledad offers higher efficiency than the one installed in Barranquilla; and regarding the efficiency of the racks, Soledad's rack is more efficient than Barranquilla's, concerning power and space, although the difference is not substantial.

\section{Conclusion}

During this research, the energy efficiency metrics applied to the data centers of the ITSA University Institution, at Barranquilla and Soledad campuses, were evaluated. Each of these metrics is recognised in the scientific field and are valid to determine if a data center is friendly to the environment. It is essential to take them into account, to undertake improvement projects that have a favorable impact on the environment that surrounds us.

As a compendium of each metric, the following can be said. DCiE efficiency metric indicates that the efficiency of the infrastructure of the data centers of the ITSA University Institution can improve its efficiency, since the current performance is inefficient in Barranquilla, and is average in Soledad. PUE efficiency metric confirms the results obtained with the previous metric, however, it is recommended that this metric is evaluated based on an average of measures for periods of time established by the analyst, to control and monitor the efficiency strategies energy implemented. The efficiency of the HVAC System metric allows calculating the relationship of energy efficiency between HVAC equipment and IT equipment. In our case, it indicated that the Barranquilla data center HVAC system is efficient and therefore its optimization is potentially small. On the other hand, the data center of Soledad has good the energy efficiency of the HVAC system, is possible to optimise it. The data centers of the University Institution ITSA, have an inefficient use of energy, even though the HVAC system installed in both data centers are relatively efficient, so it is recommended to carry out an improvement plan that optimizes energy efficiency. SWaP Efficiency is a metric initially presented by Sun to allow the comparison of different servers regarding power and space, however, using the same principles can be used for other network and storage devices. In the case of our research, we could see which of the installed devices are being more efficient with the use of energy compared to the others; it could also be observed that Soledad's data center is a little more efficient than Barranquilla's concerning the power space ratio.

As future work starting from this project, the following could be developed: propose a multicriteria methodology to evaluate the energy performance of data centers or perform an analysis of the practices 
used in different data centers, to improve energy consumption [15][16]. Even propose the design of an application based on Internet of Things (IoT) to measure the performance, consumption levels of data center [6]. Another future work that can be done is to calculate the gap between the real values obtained from each metric versus the standard values that should be and analyze how far we can be from what is really a data center friendly to the environment.

\section{References}

[1] E. Baccour, S. Foufou, R. Hamila, Z. Tari, and A. Y. Zomaya, "PTNet: An efficient and green data center network," J. Parallel Distrib. Comput., vol. 107, pp. 3-18, Sep. 2017.

[2] M. S. Obaidat, A. Anpalagan, I. Woungang, Y. Zhang, and N. Ansari, "Green Data Centers," in Handbook of Green Information and Communication Systems, Academic Press, 2013, pp. 331-352.

[3] L. Hernandez and G. Jimenez, "Characterization of the current conditions of the itsa data centers according to standards of the green data centers friendly to the environment," Adv. Intell. Syst. Comput., vol. 574, pp. 329-340, 2017.

[4] J.-M. Pierson, Large-scale Distributed Systems and Energy Efficiency: A Holistic View, Reimpresa. New Jersey, 2015.

[5] A. Shehabi, S. J. Smith, N. Horner, I. Azevedo, R. Brown, J. Koomey, E. Masanet, D. Sartor, M. Herrlin, and W. Lintner, "United States Data Center Energy Usage Report," 2016.

[6] L. Hernandez, A. Pranolo, I. Riyanto, Y. Calderon, and H. Martinez, "Design of a System for Detection of Environmental Variables Applied in Data Centers," in 2017 3rd International Conference on Science in Information Technology (ICSI Tech 2017), 2017, pp. 389-395.

[7] R. Hernandez Sampieri, C. Fernandez Collado, and M. del P. Baptista Lucio, Metodología de la investigación. 2010.

[8] Wang and S. U. Khan, "Review of performance metrics for green data centers: A taxonomy study," J. Supercomput., vol. 63, no. 3, pp. 639-656, 2013.

[9] M. Sharma, K. Arunachalam, and D. Sharma, "Analyzing the Data Center Efficiency by Using PUE to Make Data Centers More Energy Efficient by Reducing the Electrical Consumption and Exploring New Strategies," Procedia Comput. Sci., vol. 48, pp. 142-148, Jan. 2015.

[10] 42U Data Center Solutions, "42U Data Center Solutions," 2018. [Online]. Available: https://www.42u.com/measurement/pue-dcie.htm. [Accessed: 21-Jul-2018].

[11] Pablo Fernández, “Las nuevas métricas de Green Grid para la eficiencia energética," Silicon, Mar-2009.

[12] EPA, "Report to Congress on Server and Data Center Energy Efficiency Public Law 109-431," Berkeley, California, 2007.

[13] J. Yuventi and R. Mehdizadeh, "A critical analysis of Power Usage Effectiveness and its use in communicating data center energy consumption," Energy Build., vol. 64, pp. 90-94, Sep. 2013

[14] W. Lintner, B. Tschudi, and O. VanGeet, "Best Practices Guide for Energy-Efficient Data Center Design," U.S Dep. Energy, no. March, p. i-24, 2011.

[15] B. Dennis, "Five Ways to Reduce Data Center Server Power Consumption," Green Grid, 2009.

[16] J. Judge, J. Pouchet, A. Ekbote, and S. Dixit, "Reducing data center energy consumption," ASHRAE J., vol. 50, no. November, 2008. 